\title{
Abordaje conservador de una rotura traqueal en un niño tras una contusión
}

\author{
Conservative management of tracheal rupture in a child after blunt trauma
}

Dra. Gonul Kucuka, Dr. Ufuk Ates ${ }^{a}$, Dra. Gulnur Gollu y Dr. Aydin Yagmurlu

\section{RESUMEN}

La rotura traqueal tras una contusión es rara, aunque potencialmente mortal. En general, se recomienda el tratamiento quirúrgico para la rotura traqueal, aunque también se ha informado recientemente el abordaje conservador en los pacientes con signos vitales y parámetros respiratorios estables. El objetivo de este estudio es informar sobre un caso de rotura traqueal tras una contusión en el cuello producto de un accidente de bicicleta que se trató de manera conservadora.

Palabras clave: afección de la tráquea, lesiones cervicales, heridas, traumatismo cerrado.

http:/ /dx.doi.org/10.5546/aap.2016.e454

Texto completo en inglés: http:/ / dx.doi.org/10.5546/aap.2016.eng.e454

\section{INTRODUCCIÓN}

La rotura traqueal es una afección rara aunque potencialmente mortal. La incidencia de las lesiones traumáticas de las vías aéreas es del 0,4 en el caso de las contusiones. ${ }^{1}$ En general se producen como resultado de una contusión, pero también pueden ocurrir tras un episodio grave de tos o vómitos, o pueden ser de origen iatrogénico, secundarias a la dilatación de una estenosis, una broncoscopía rígida o la intubación endotraqueal. ${ }^{2} \mathrm{El}$ diagnóstico suele retrasarse o pasarse por alto; sin embargo, recientemente ha aumentado la cantidad de informes sobre rotura traqueal debido a las mejoras en la atención de los pacientes que sufren un traumatismo. ${ }^{3}$ Los pacientes estables con diagnóstico de rotura traqueal podrían ser sometidos a un tratamiento quirúrgico innecesario, que también incrementa la morbimortalidad. El objetivo de este artículo es presentar el caso de un niño de seis años con rotura traqueal tratado de manera conservadora, cuya evolución fue favorable.

a. Escuela de Medicina de Ankara Üniversitesi,

Departamento de Cirugía Pediátrica, Ankara, Turquía.

Correspondencia:

Dra. Gulnur Gollu: drggollu@yahoo.com

Financiamiento: Ninguno.

Conflicto de intereses: Ninguno que declarar.

Recibido: 9-5-2016

Aceptado: 23-6-2016

\section{Caso clínico}

Un niño de seis años tuvo un accidente de bicicleta y sufrió un traumatismo directo contra el manubrio; se lo hospitalizó con dolor e inflamación del cuello. En la exploración física se observó enfisema subcutáneo que se distribuía desde la mandíbula hacia el esternón, las costillas y el omóplato. Los parámetros hemodinámicos y respiratorios, incluida la oximetría, eran normales. En la radiografía torácica se observaron enfisema subcutáneo y neumomediastino (Figura 1). En la tomografía computarizada (TC) (Figura 2) y la broncoscopia virtual (Figura 3) se apreciaron enfisema subcutáneo, neumomediastino y una rotura traqueal longitudinal de 1,5 cm de largo, $2 \mathrm{~cm}$ por encima de la carina en la pared posterior de la tráquea. Se supervisaron atentamente los parámetros clínicos y respiratorios durante la inserción de una cánula sobre el esternón para drenar el enfisema subcutáneo. Durante el primer día recibió tratamiento con oxígeno nasal. El paciente recibió antibioticoterapia con $100 \mathrm{mg} / \mathrm{kg} /$ día de cefalosporina por vía intravenosa, y paracetamol por vía intravenosa a modo de analgésico. Se dejó la cánula colocada durante cuatro días para drenar el enfisema subcutáneo; la radiografía torácica de control del cuarto día era normal. El tratamiento antibiótico

FIgURA 1: Radiografía de tórax. Enfisema subcutáneo y neumomediastino

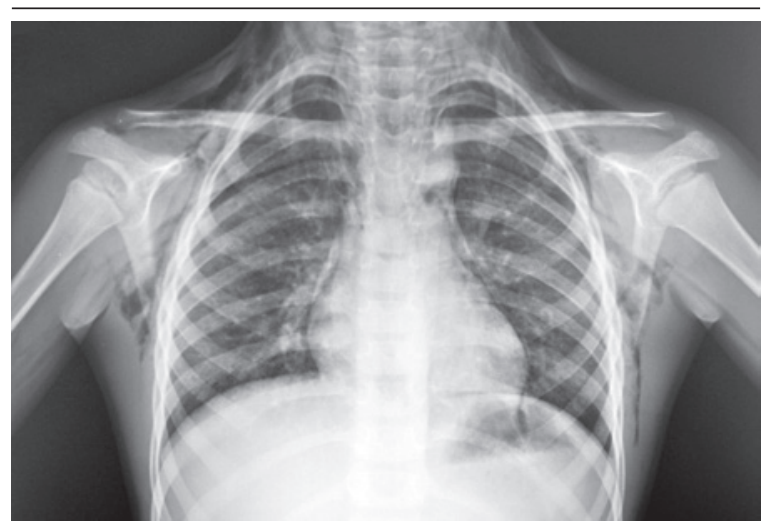


intravenoso duró seis días. El paciente se recuperó rápidamente, su estado clínico era estable y la radiografía torácica, normal; recibió el alta al sexto día. Durante los tres años de seguimiento no presentó ningún problema. Continuó clínicamente estable, no tuvo dificultad respiratoria ni estridor, y las radiografías torácicas fueron normales en los seguimientos. Se obtuvo el consentimiento informado de los padres del niño para la publicación del caso.

\section{DISCUSIÓN}

La rotura traqueal es una lesión rara, cuya morbimortalidad es elevada. ${ }^{3}$ La tráquea puede dañarse debido a uno de tres mecanismos: traumatismo de alto impacto en el tórax con la glotis cerrada, lesión por aceleración o desaceleración, o golpe contra el cuello durante la flexión o hiperextensión. ${ }^{3,4}$ Un traumatismo menor también puede provocar una rotura traqueal, especialmente en la porción membranosa de la tráquea, la parte más débil de la laringotráquea. La rotura puede ser transversal, longitudinal o compleja. ${ }^{3}$ El enfisema subcutáneo es el signo más específico del trastorno de la tráquea. ${ }^{4}$ Debe sospecharse en presencia de neumomediastino, con o sin neumotórax, hemoptisis y enfisema subcutáneo. ${ }^{3}$ El enfisema subcutáneo indica una lesión de las vías respiratorias, pero no siempre es evidente durante la exploración inicial. A los pacientes cuyo estado respiratorio es estable se les debe realizar una evaluación radiológica. La radiografía torácica podría revelar un enfisema subcutáneo, neumotórax o neumomediastino. ${ }^{4}$ Si se sospecha rotura traqueal y el paciente se encuentra estable, deben realizarse una TC de tórax y una broncoscopía virtual, que es una imagen tridimensional reconstruida mediante imágenes de la TC helicoidal multicorte. Esta técnica es menos invasiva que la traqueoscopía, que conlleva el riesgo de empeorar la afección, especialmente al momento de administrar la anestesia durante la ventilación manual mediante el aumento de la presión de las vías respiratorias. ${ }^{4}$ El tratamiento conservador incluye antibióticos y analgésicos, oxígeno y drenaje del enfisema con una cánula o catéter. La dificultad respiratoria es el principal factor determinante del tipo de tratamiento. Las heridas extensas con fuga de aire significativa y el estado inestable se tratan mediante reparación quirúrgica.

Nakamori y col. también informaron un caso de rotura traqueal diagnosticada con una broncoscopía virtual. ${ }^{5}$ Kaloud y col. recomendaron la reparación quirúrgica de las roturas de más de $1 \mathrm{~cm}$ de largo. ${ }^{6}$ Kuhne y col., Merol y col. y D'Odement y col. informaron sobre el éxito del abordaje conservador de las lesiones de la tráquea. ${ }^{3,4,7}$ La mayoría de los autores realizan la broncoscopía para diagnosticar la rotura, pero no realizan la TC porque la consideran un procedimiento innecesario. Sin embargo, la broncoscopía, que es un estudio posiblemente riesgoso, podría ser innecesaria en las lesiones bien toleradas. Merol y col., también consideran que no debería realizarse una traqueoscopía como parte del tratamiento inicial de los pacientes estables con un diagnóstico obvio según la exploración clínica, las radiografías y la $\mathrm{TC}^{4}$

Por último, debe considerarse el abordaje conservador en los casos con un traumatismo menor, estado estable y diagnóstico preciso.
FIgURA 2. Tomografía computarizada torácica. Rotura traqueal (flecha blanca)

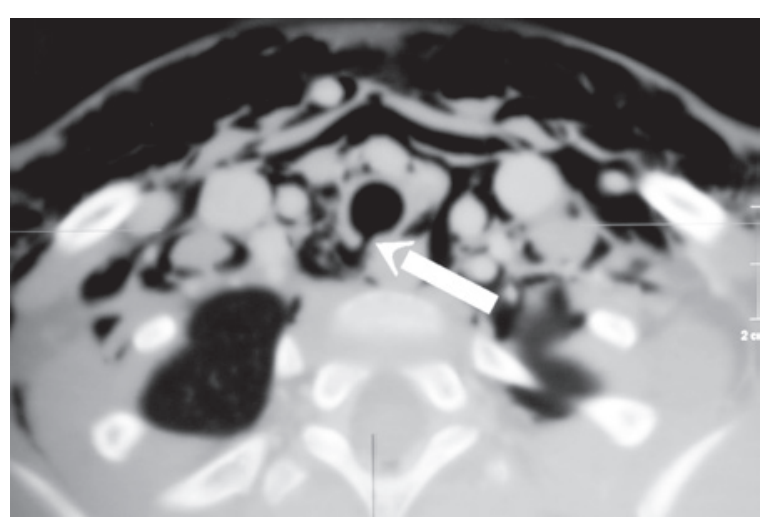

FIGURA 3. Broncoscopía virtual. Rotura traqueal longitudinal 2 cm por encima de la carina en la pared posterior de la tráquea

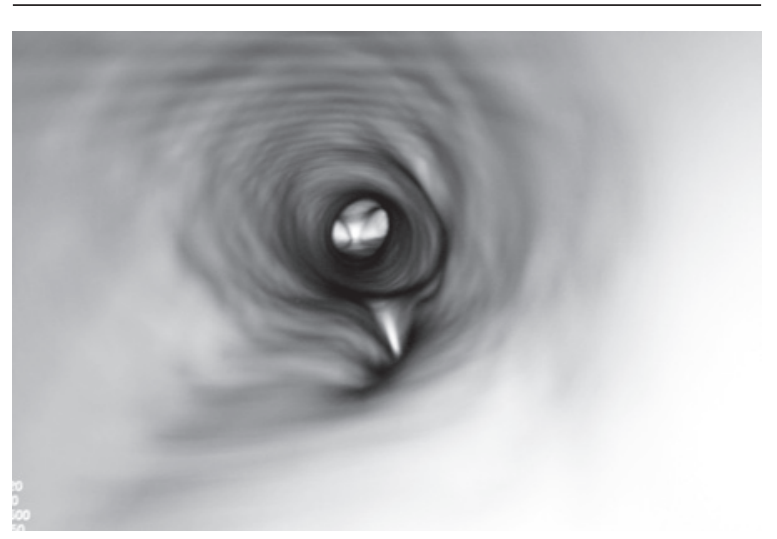


La parte más importante y dificultosa de la rotura traqueal es el diagnóstico preciso de la lesión. El seguimiento de estos pacientes es muy importante ya que existe el riesgo de estenosis traqueal. Wood y col. publicaron la mayor serie de casos sobre los resultados del abordaje conservador de las contusiones de la tráquea en niños y establecieron que cinco de los ocho pacientes con rotura traqueal desarrollaron estenosis en el seguimiento a dos años, y que tres de estos pacientes requirieron una nueva cirugía. ${ }^{8} \mathrm{Si}$ bien la mayoría de los autores recomiendan el tratamiento quirúrgico de las lesiones traqueobronquiales, el abordaje conservador también es viable, especialmente en las lesiones bien toleradas con supervisión atenta de los parámetros hemodinámicos y respiratorios. La broncoscopía virtual debe reservarse para los pacientes en buen estado para evitar una exploración riesgosa e innecesaria en aquellos que podrían recibir tratamiento no invasivo y evitar los procedimientos quirúrgicos abiertos en los pacientes más estables.

\section{REFERENCIAS}

1. Prokakis C, Koletsis EN, Dedeilias P, Fligou F, et al. Airway trauma: a review on epidemology, mechanisms of injury, diagnosis and treatment. J Cardiothoracac Surg 2014;9:117.

2. Stevens MS, Mullis TC, Carron JD. Spontaneous tracheal rupture caused by vomiting. Am J Otolaryngol 2010;31(4): 276-8.

3. Kuhne CA, Kaiser GM, Flohe S, Beiderlinden M, et al. Nonoperative management of tracheobronchial injuries in severely injured patients. Surg Today 2005;35(7):518-23.

4. Poli-Merol ML, Belouadah M, Parvy F, Chauvet P, et al. Tracheobronchial injury by blunt trauma in children: Is emergency tracheobronchoscopy always necessary? Eur J Pediatr Surg 2003;13(6):398-402.

5. Nakamori Y, Hayakata T, Fujimi S, Satou K, et al. Tracheal rupture diagnosed with virtual bronchoscopy and managed nonoperatively: a case report. J Trauma 2002;53(2):369-71.

6. Kaloud H, Smolle-Juettner FM, Prause G, List WF. Iatrogenic ruptures of tracheobronchial tree. Chest 1997;112(3):774-8.

7. D'Odemont JP, Pringot J, Goncette L, Goenen M, et al. Spontaneous favorable outcome of tracheal laceration. Chest 1991;99(5):1290-2.

8. Wood JW, Thornton B, Brown CS, Mclevy JD, et al. Traumatic tracheal injury in children: a case series supporting conservative management. Int J Pediatr Otorhinolaryngol 2015;79(5):716-20. 